\title{
Coping Styles with Student Misbehavior as Mediators of Teachers' Classroom Management Strategies
}

\author{
Van Dat Tran ${ }^{1}$ \\ ${ }^{1}$ Research and International Relations Office, An Giang University, Vietnam \\ Correspondence: Van Dat Tran, Research and International Relations Office, An Giang University, Vietnam. Tel: \\ 84-76-256-565 (1714).E-mail: tvdat@agu.edu.vn
}

Received: September 26, 2015

Accepted: October 6, 2015

Online Published: October 15, 2015

doi:10.5430/ijhe.v5n1p1

URL: http://dx.doi.org/10.5430/ijhe.v5n1p1

\begin{abstract}
The purpose of the present study is to identify how teachers' use of various coping styles with student misbehavior, and the extent to which these relate to their classroom management techniques - punishment, recognition and reward, hinting, discussion, and aggression. It examines data from 397 junior high school teachers in Vietnam. The results obtained from correlation analyses indicated that coping styles mediated the relationship between teachers' concerns about student misbehavior and their use of classroom management techniques. The findings obtained from the data analyses indicated that teachers who use passive avoidant strategies employ more aggression and punishment techniques towards student misbehavior. Conversely, teachers who use more social problem solving and relaxation strategies use more inclusive management techniques such as recognition and reward, discussion, and hinting. Implications of these findings are discussed.
\end{abstract}

Keywords: Classroom management techniques, Student misbehavior, Teacher stress, Coping styles

\section{Introduction}

Of all of activities of a teacher, effective classroom management is one of the most important (Lewis, 1999) to increase the provision of quality instruction, and to decrease student misbehavior, and distraction from schoolwork (Kennedy, 1996). Classroom management skills are a significant aspect of professional practice, with broad implications for student learning and welfare (Lewis, 2011, p.4). According to Lewis (2001), "one purpose of classroom discipline is to establish order, to permit teachers to instruct students in the formal curriculum of the school... A second purpose is to provide an appropriate educational experience to shape the students' values and to teach them about the rights of individuals" (p.1207). A critical component of teachers' sense of professional efficacy is the ability to manage students effectively (McCormick \& Shi, 1999). One of the most stressful parts of many teachers' professional lives is to find the most effective management techniques to cause behavior change and preventing the increase of classroom discipline problems (Hart, Wearing, \& Conn, 1995). Recent research has showed that the various techniques of classroom management have effective effects on levels of student responsibility and misbehavior in classes, distraction from schoolwork (Lewis, 2001; Lewis, Romi, Xing, \& Katz, 2005); attitude to schoolwork, teachers and to the students who misbehave (Lewis et al., 2005; Lewis, Romi, Qui, \& Katz, 2008; Romi, Lewis, \& Katz, 2009); and connection to school (Roache \& Lewis, 2011). Results of some studies conducted in Australia and others in Israel and China (Lewis et al., 2005; Lewis et al., 2008) indicate that recognition of responsible behavior, and discussions with misbehaving students about the effect their behavior has on other students, are clearly productive because students experiencing these techniques are more responsible, less distracted, and more positive towards their teachers and schoolwork. In contrast, teacher aggression, comprising strategies such as group punishment, humiliation and yelling in anger, appears to be associated more with student misbehavior and higher levels of negative student attitudes towards learning in classroom. In a study into the perceptions of 592 primary students and 2938 secondary students in Australia, Lewis (2001) reports that

More responsible students are in classes where teachers involve them more in the decision making and are seen to provide more non-directive hints, recognition for good behavior and discussion with misbehaving students to allow them to understand the impact of their behavior on others and to work out how to behave better (p. 312). 
The present study revealed that, from the view of students, the teachers were believed to be characterized by two distinct management styles. One was identified as "coercive", and included punishment and aggression (e.g. increasing levels of consequences, yelling angrily, making sarcastic comments, etc.). The other style was called "relationship based management", which comprised discussion, hints, recognition and rewards, and involvement (e.g. rewarding and praising individual students for behaving well, discussing behavior issues with students, etc.). Lewis (2001) reports that

Students who receive more relationship based management are less disrupted when teachers deal with misbehavior and generally act more responsibly in that teacher' class. In contrast, the impact of coercive management appears to be more student distraction from work and less responsibility (p.315).

In a comparative study into the relationship between students' perceptions of the classroom management techniques and student misbehavior of over 748 teachers and 5521 students in Australia, China, and Israel, (Lewis, Romi, Qui \& Katz, 2005) report that "students who reported greater levels of misbehavior were more likely to perceive aggression by teachers, although no other strategy produced statistically significant univariate results" (p.737). A recent study by Hyman and Snook (2002) also emphasizes the negative effect of harsh and punitive management techniques. They conjecture that "unnecessarily harsh and punitive disciplinary practices against students create a climate that contributes to school violence. This issue is little recognized and scarcely researched" (p.489). The findings of the above studies reinforced those of Miller, Ferguson, and Byrne (2000), who report that teacher behavior, such as shouting all the time, unfairly blaming students, picking on kids, and being rude, may cause classroom misbehavior, and stimulate levels of student resistance misbehavior. In sum, classroom management and student responsibility as well as misbehavior have been studied in Australia (Lewis, 2001; Oswald, 1995), China (Gao, 1998; Jin \& Cortazzi, 1998; Peng, 1993), and Israel (Friedman, 1994; Kaplan, Gheen, \& Midgley, 2002; Romi \& Freund, 1999). Lewis (2001) argued that

In establishing the possibility of a strong connection between management strategies and the development of student responsibility, this study indicates that it may be possible to have a substantial impact on students' commitment to the protection of human rights by attending to teachers' classroom disciplinary style (p.317).

Teachers' coping styles have associated with their stress from student misbehavior. Normally, stress is considered as an outcome of a person appraising his or her environment as one which taxes or exceeds his or her resources. Such environment is consequently perceived as threatening (Lazarus \& Folkman, 1984). Coping is typically is viewed as the cognitive and effective responses used by an individual to deal with problems encountered in everyday life. Specifically, coping is defined as "the ongoing cognitive and behavioral efforts to manage specific external and/or internal demands that are appraised as taxing or exceeding the resources of the person" (Lazarus, 1993, p.237). The cost of workplace stress is a critical issue in many professions, especially those involved in social services, such as teaching (Roache, 2008). The teachers may suffer from workplace stress such as factors intrinsic to the job (e.g. classroom management), role in organization (e.g. role ambiguity or conflict) career development (e.g. fixed contracts), work relationships (e.g. poor collegiate support) and organizational structure or climate (e.g. little involvement in decision-making) (Roache, 2008). The result of high levels of workplace stress can result in cynicism, depersonalization of students, and emotional exhaustion in response to chronic stress if a teacher has limited or ineffective coping responses (Lewis, Romi \& Roache, 2011).

In the present study, the stressor of interest is the inappropriate behavior of students, and 'coping' refers to cognitive and affective teacher responses that arise in response to a stress associated with student misbehavior. These responses are utilized to restore the equilibrium by solving the problem, minimizing it, accommodating to it, or attempting to avoid it. Coping is essentially a dynamic phenomenon whereby the individual and the environment are engaged in an interactive process (Lewis, 1999). Generic coping responses consist of specific feelings, thoughts, and actions. Not all coping strategies are to reduce distress, and that certain coping strategies, such as avoidance (Cronkite \& Moos, 1984) or restricting one's expectations (Menaghan \& Merves, 1984), may exacerbate distress. According to Chan (1998), when coping strategies such as problem solving and seeking support are involved, the direct effect of stressors on distress is considerably reduced.

Lewis (1999) examined the relationship between discipline and coping among teachers. He examines teachers' estimations of the stress that arises when they are unable to discipline students as they would ideally prefer and the way teachers cope with any stress that arises. Results showed that teachers who report more stress were those most interested in empowering their students in the decision-making process. Associated with increased concern is a greater use of such coping responses as worry, self-blame, tension reduction, wishful thinking and keeping concerns to oneself. The most concerned teachers also expressed a greater tendency to get sick as a result of stress. According 
to Lewis, these findings suggested the need for professional development curricula for teachers to assist them in effectively sharing power with students and in reflecting upon a range of more productive coping strategies. In addition, Lewis, Roache, and Romi (2011) report the relationships between coping styles of teachers and the classroom based classroom management techniques they use to cope with student misbehavior. Results show that coping styles play a significant role in mediating the relationship between teachers' concerns about student misbehavior and their use of classroom management techniques. Specifically, teachers who are more concerned about student misbehavior use more aggressive classroom management, and teacher who perceived their classes to contain more badly behaved students make more use of punishment and aggression. In addition, teachers who use avoidant and passive coping strategies employ more coercion and aggression towards students, while teachers who use more socially oriented problem solving coping strategies use more inclusive management techniques such as discussion, hinting and rewarding.

In the settings of Vietnamese junior high schools, student misbehavior and school violence, two serious problems have been on the rise (Ministry of Education and Training [MOET], 2010). Although Vietnamese students are expected to learn about the rights and responsibilities of citizens, respect the teacher's authority, and concern themselves with the rights of others (National Assembly of the Socialist Republic of Vietnam [NASRV], 2008), the increasing frequency of student misbehavior and school violence has been a serious concern for educators. The data provided by MOET, (2010) show that there were about 16.000 incidents of classroom misbehavior (e.g., dishonesty and disrespect for traditional authority figures), and school violence (e.g., cruelty to peers, bigotry and hate crime), which occurred in Vietnamese junior high schools. However, very few studies have systematically investigated the relationships between different types of management techniques and student behavior, coping styles towards student misbehavior in Vietnamese classrooms. Therefore, the purposes of the present study are to examine the relationship between the stress teachers feel as a result of student misbehavior, and identify how teachers' use of various coping styles - passive avoidant, social problem-solving, and relaxation with student misbehavior, and the extent to which these relate to their classroom management techniques - punishment, recognition and reward, hinting, discussion, and aggression. This study may provide Vietnamese teachers with useful information to choose the most suitable classroom management techniques for decreasing student misbehavior, and student distraction from schoolwork, and increasing student learning.

\section{Research Method}

\subsection{Participants}

Information regarding teachers' perceived misbehavior, levels of concern, classroom disciplines and coping styles was gathered from 397 junior high school teachers in An Giang, a large urban province in the Southwest part of Vietnam (Table 1 ). The teachers were evenly distributed by gender (females $=201$, account for 50.6 percent; males $=$ 196, account for 49.4 percent). Their age ranged from 23 to 46. They taught in grade level from grade 10 to grade 12 . There were a total of 15 junior high schools which provided data for this investigation were volunteers. The response rate for schools was very high $(95.1 \%)$. This is consistent with the greater concern about issues of classroom disciplines and coping styles at this school level.

Table 1. Distribution of sample by school level

\begin{tabular}{lcccc}
\hline Level & $\mathrm{n}$ (teachers) & \multicolumn{2}{c}{ Gender } & $\mathrm{n}$ (schools) \\
\cline { 3 - 4 } & & Female & Male & \\
\hline Grade 10 & 124 & 72 & 52 & 5 \\
Grade 11 & 96 & 44 & 52 & 3 \\
Grade 12 & 177 & 85 & 92 & 7 \\
Total & 397 & 201 & 196 & 15 \\
\hline
\end{tabular}

Note: $\mathrm{n}=397$

\subsection{Instruments}

The 397 teachers who participated in this study were asked to complete a survey with reference to the class they would normally be teaching after completing the survey. The questions focused on assessing the level of misbehavior in this class, the concern associated with this misbehavior, their perceptions of the way they attempted to cope with this concern and the management strategies they employed in response to the misbehavior. The teachers' responses $(\mathrm{n}=397)$ to the scales were checked for internal consistency by computing respective Cronbach Alpha coefficients. Table 2 reports the means scores, standard deviations and internal consistency (Cronbach Alpha) coefficients for each of the measures used in this study. 
Table 2. Means, standard deviation (SD), and alpha coefficient $(\alpha)$ of independent and dependent variables

\begin{tabular}{llcccc}
\hline & Variable & Mean & Std. Dev. & Alpha & No. Items \\
\hline Misbehavior & & & & & \\
& Perceived misbehavior & 2.97 & 1.33 & $\mathrm{n} / \mathrm{a}$ & 1 \\
& Level of concern & 3.14 & 1.01 & $\mathrm{n} / \mathrm{a}$ & 1 \\
Classroom discipline & & & & \\
& Punishment & 3.11 & 3.54 & .71 & 4 \\
& Recognition and reward & 4.21 & 2.57 & .69 & 4 \\
& Hinting & 4.20 & 3.46 & .77 & 4 \\
& Discussion & 4.12 & 3.53 & .73 & 4 \\
& Aggression & 2.94 & 4.42 & .76 & 4 \\
& & & & & \\
& Passive avoidant & 3.24 & 4.03 & .75 & 7 \\
& Social problem-solving & 3.57 & 5.09 & .72 & 6 \\
& Relaxation & 3.76 & 3.80 & .69 & 4 \\
\hline
\end{tabular}

Note: $\mathrm{n}=498$

\subsubsection{Student Misbehavior and Concern}

The question designed to measure perceived student misbehavior focused on the number of students who were misbehaving. The teachers were asked: "How many students misbehave in the class you would normally teach next?" The 5 responses available were: None; Hardly any; Some; Most; and Nearly all, coded 1 to 5 respectively. The number of students engaging in misbehavior would effectively capture sufficient variance to act a useful predictor of teacher concern. Therefore, to assess levels of teacher concern, the question provided asked: "To what extent is the issue of classroom discipline and student misbehavior an issue of concern to you?" The 5 responses were: Of no concern; Of almost no concern; Of minor concern; Of moderate concern; and Of major concern, coded 1 to 5 respectively.

\subsubsection{Measuring Classroom Management Strategies}

A shortened, 24-item version of the 35-item questionnaire developed by Lewis (2001) was used to measure the students' perceptions of classroom management strategies. These 24 items were utilized to assess five classroom management strategies. The strategies measured were punishment, recognition and reward, hinting, discussion, and aggression. Each strategy measured had four items. The first strategy, called punishment, contained 4 items (Gives out consequences to students who misbehave (e.g. move seats, detention); Increases the level of consequence if students will not do the right thing (e.g. move seats, detention); Increases the level of consequence if a misbehaving student argues; and Increases the level of consequence if a misbehaving student stops when told, but then does it again). The second strategy, called recognition and rewards, consisted of 4 items (Rewards the class when students behave well; Rewards individual students who behave properly; Praises individual students for good behavior; and Praises the class for good behavior). The third strategy, called hinting, comprised 4 items (Describes what students are doing wrong, and expect them to stop; Asks students questions like "What are you doing?" to get them think about how to behave better; Reminds misbehaving students about the class rules; and Describes how students are misbehaving to make them decide whether to stop or not). The fourth strategy, called discussion, contained 4 items (Discusses students' behavior with them to allow them to figure out a better way to behave in future; Lets students talk about their side of things so that it can be clearly understood; Gets students to understand why their behavior is a problem for others by discussing it with them; and Gets students to change the way they behave by helping them understand how their behavior affects others). The final strategy, called aggression, consisted of 4 items (Yells angrily at students who misbehave; Deliberately embarrasses students who misbehave; Keeps the class in because some students misbehave; and Makes sarcastic comments to students who misbehave). Each item required a response on a 5-point scale to indicate how frequently the teacher acted in such a manner "when trying to deal with misbehavior". The response alternatives for each item were "Never, Hardly ever, Some of the time, Most of the time, and Nearly all the time," and were coded from 1 to 5 , respectively. 


\subsubsection{Teacher Coping Styles}

The 17-item version of the questionnaire developed by Lewis (2001) was used to measure the three coping styles. The first coping style, passive avoidant coping (strategies involving wishing things would better, blaming oneself, varying eating or sleeping patterns, and getting sick), comprised seven strategies. These include: Worry about what will happen to me; Wish a miracle will happen to make things turn out well; Blame myself; Don't let others know about my problem; I get sick; Shut myself off from the problem so I can try and ignore it; and Find a way to let off steam, for example cry, scream, drink, take drugs. The second coping style, called social problem solving (strategies involving solving the problem by working hard, seeking professional help and social support, joining with others to deal with the problem, and spending time with good friends), comprised six strategies. These include: Look for support and encouragement from others; Work hard; Join with others to deal with the problem, e.g. organize a petition, attend a meeting; Ask a psychologist or other professional person for help; Spend more time with a good friend; and Work out a way of dealing with the problem. The third coping style, called relaxation (strategies involving doing something relaxing, doing sport, retaining a sense of humor, and accepting one's best attempts to deal with the issue), comprised four strategies including Look on the bright side of things and think of all that is good; Relax, e.g. watch TV, play computer games, go for a walk; Keep fit and healthy, e.g. play sport; and Try to be funny. The three coping styles examined in the study (Lewis, 2001) were assessed by a total of 17 questionnaire items, each of which required a response on a 5-point scale to indicate how frequently the teacher acted such a thing "when trying to cope with student misbehavior and classroom management". The 5 responses were: Never, Rarely, Sometimes, Often, and Very often coded from 1 to 5, respectively.

\subsection{Procedure}

All of 397 teachers in 15 junior high schools were invited to participate in this study after the permission for access to the study was obtained from the principals of schools and the Department of Education and Training. All participants were clearly explained that they were free to withdraw from the research at any time. The privacy of participants was ensured concerning the information they supplied in the questionnaires. No questions or statements required the participants to provide their names or schools where they are teaching. The researcher administered the questionnaires to the principals of each school, who delivered the questionnaires to the teachers. All teachers were asked to specify one of six subject areas taught (Mathematics, Physics, Chemistry, Biology, English and History). The teachers were also required to focus on one class in that subject area when completing the questionnaires. Participants completed the questionnaires in 60 minutes. The researcher personally collected the completed questionnaires from the principals of each school.

\subsection{Data Analysis}

Pearson product-moment correlation coefficients were used to investigate associations among perceived misbehavior, concerned misbehavior level, classroom management techniques, and coping styles. All analyses were tested for significance at the .05 level.

\section{Results and Discussion}

\subsection{Levels of Student Misbehavior and Teacher Concern}

The results in Table 2 show that on average, teachers expected slightly more than 'hardly any' of the students in their classes to misbehave. The average item mean for perceived misbehavior was between 'hardly any' and 'some', closer to some ( $\mathrm{M}=2.97$ on the 5 point scale). This appeared to cause, on average, minor concern about student misbehavior. The average mean for level of concern about student misbehavior was between 'minor concern' and 'moderate concern' ( $\mathrm{M}=3.14$ on the 5 point scale).

\subsection{Teachers' Coping Styles}

The results in Table 2 indicate that teachers reported they more than sometimes attempt to remain socially connected, while trying to solve the problem. The average item mean for social problem-solving strategies was between 'sometimes' and 'often', nearer to often ( $\mathrm{M}=3.57$ on the 5 point scale). The teachers sometimes turn to relaxing activities and less frequently engage in passive avoidant strategies. The average item mean for relaxing strategies was between 'sometimes' and 'often', closer to 'often' $(M=3.76)$, while the average item mean for passive avoidant strategies was between 'sometimes' and 'often', closer to 'often' $(M=3.24)$. 


\subsection{Teachers' Classroom Management Techniques}

An inspection of the mean scores in Table 2 indicates that, to establish order in the classroom, teachers most commonly allowed students to have input into expectations, recognized and rewarded appropriate behavior, used hinting to highlight that there was a problem with students' behavior, held discussion with students who misbehave in a bid to allow them to see the effect their behavior had on others. All of these techniques were used, on average, between 'often' and 'very often'. The average item means for recognition and rewards, hinting, and discussion strategies were 4.21, 4.20, and 4.12 respectively. Punishment strategies were used between 'some of the time' and 'most of the time', while aggression 'hardly ever' occurred.

\subsection{The Relationships between Measures}

The relationships between coping styles strategies and other measures - teachers' perceived misbehavior, level of concern, punishment, recognition and rewards, hinting, discussion, and aggression are reported in Table 3 .

Table 3. The relationship between coping styles strategies and other measures

\begin{tabular}{lrrrrrrrrrr}
\hline \multicolumn{1}{c}{ Measure } & 1 & 2 & 3 & 4 & 5 & 6 & 7 & 8 & 9 & 10 \\
\hline 1. Perceived misbehavior & - & & & & & & & & & \\
2. Level of concern & $.42^{* *}$ & - & & & & & & & \\
3. Punishment & $.37^{* *}$ & $.38^{* *}$ & - & & & & & & \\
4. Recognition and reward & $.36^{* *}$ & $-.41^{* *}$ & $-.47^{* *}$ & - & & & & & \\
5. Hinting & $.34^{* *}$ & $-.36^{* *}$ & $-.32^{* *}$ & $.29^{*}$ & - & & & & \\
6. Discussion & $-.29^{*}$ & $-.24^{*}$ & $-.39^{* *}$ & $.36^{* *}$ & $.17^{*}$ & - & & & \\
7. Aggression & $.35^{* *}$ & $.37^{* *}$ & $.31^{* *}$ & $-.43^{* *}$ & $-.21^{*}$ & $-.41^{* *}$ & - & & \\
8. Passive avoidant & $.26^{*}$ & $.19^{*}$ & $.22^{*}$ & $-.36^{* *}$ & $-.15^{*}$ & $-.37^{* *}$ & $.18^{*}$ & - & \\
9. Social problem-solving & $-.28^{*}$ & $-.21^{*}$ & $-.33^{* *}$ & $.28^{*}$ & $.31^{* *}$ & $.19^{*}$ & $-.27^{*}$ & $-.35^{* *}$ & - & \\
10. Relaxation & $-.23^{*}$ & $-.27^{*}$ & $-.26^{*}$ & $.32^{* *}$ & $.24^{*}$ & $.14^{*}$ & $-.21^{*}$ & $-.23^{*}$ & $.16^{*}$ & -
\end{tabular}

**. Correlation is significant at the 0.01 level (2-tailed).

*. Correlation is significant at the 0.05 level (2-tailed).

To examine the relationship between coping styles and classroom disciplines, two path analyses will be reported. Each investigates causal links between the variables measured in the present study. The first examines the effects of perceived student misbehavior on the teachers' expressed concern. It then documents the impact of this concern on the teachers' use of each of the classroom management strategies. The second considers the mediating the effect of each of the three coping styles on their management behavior by inserting coping responses between the teachers' concern and their choice of each of the five management strategies. Figure 1 reports the results of the first path analysis.

Figure 1 demonstrates the assumptions about causality that were tested using the path analysis. The teachers' perception of student misbehavior was positively significantly related to their level of concern over such misbehavior $(\mathrm{r}=.42, \mathrm{p}<.001)$. The finding indicated that when teachers perceived slightly more than 'hardly any' of the students in their classes to misbehave they tend to consider this issue a minor concern. This concern then leads them to respond to the misbehavior by manifesting the five management strategies. The level of concern variable was positively significantly related to punishment $(\mathrm{r}=.38, \mathrm{p}<.001)$, and aggression $(\mathrm{r}=.37, \mathrm{p}<.001)$, while this variable negatively significantly related to recognition and rewards $(r=-.41, p<.001)$, hinting $(r=-.36, p<.001)$, and discussion $(\mathrm{r}=-.24, \mathrm{p}<.005)$. Inspection of the statistically significant paths in the analysis indicates that teachers who are more concerned about student misbehavior they use more punishment (e.g. gives out consequences to students who misbehave, increases the level of consequence if a misbehaving students argues), and aggression (e.g. yells angrily at students who misbehave, deliberately embarrasses students who misbehave), and employ slightly less recognition and rewards (e.g. rewards the class when students behave well, praises individual students for good behavior), hinting (e.g. describes what students are doing wrong, and expect them to stop, reminds misbehaving students about the class rules), and discussion (e.g. discusses students' behavior with them to allow them to figure out a better way to behave in future, lets them talk about their side of things so that it can be clearly understood). In 
addition, the results also show that regardless of teachers' level of concern about student misbehavior, those who perceive their classes to contain badly behaved students make more use of punishment and aggression.

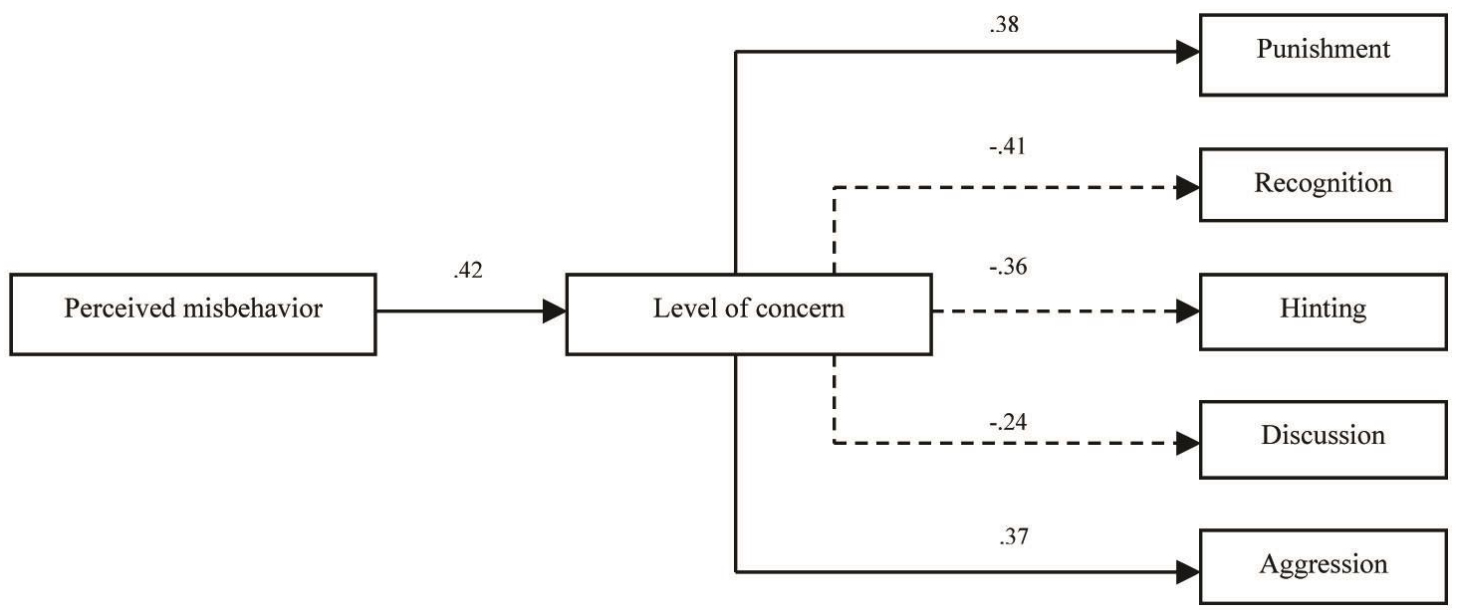

Figure 1. Relationships between perceived misbehavior, concern and management

The path analysis reported in Figure 2 considers the mediating effects of each of the three coping styles on teachers' management behavior. The findings indicated that when teachers perceived student misbehavior as a minor concern they tend to respond to misbehavior by manifesting the three coping strategies. The path analysis shows that the level of concern variable was statistically significantly related to all of three coping styles. The level of concern variable was positively significantly related to passive avoidant coping strategies $(r=.19, \mathrm{p}<.005)$, while this variable negatively significantly related to relaxation strategies $(\mathrm{r}=-.27, \mathrm{p}<.005)$, and social problem solving $(\mathrm{r}=-.21, \mathrm{p}$ $<.005)$.

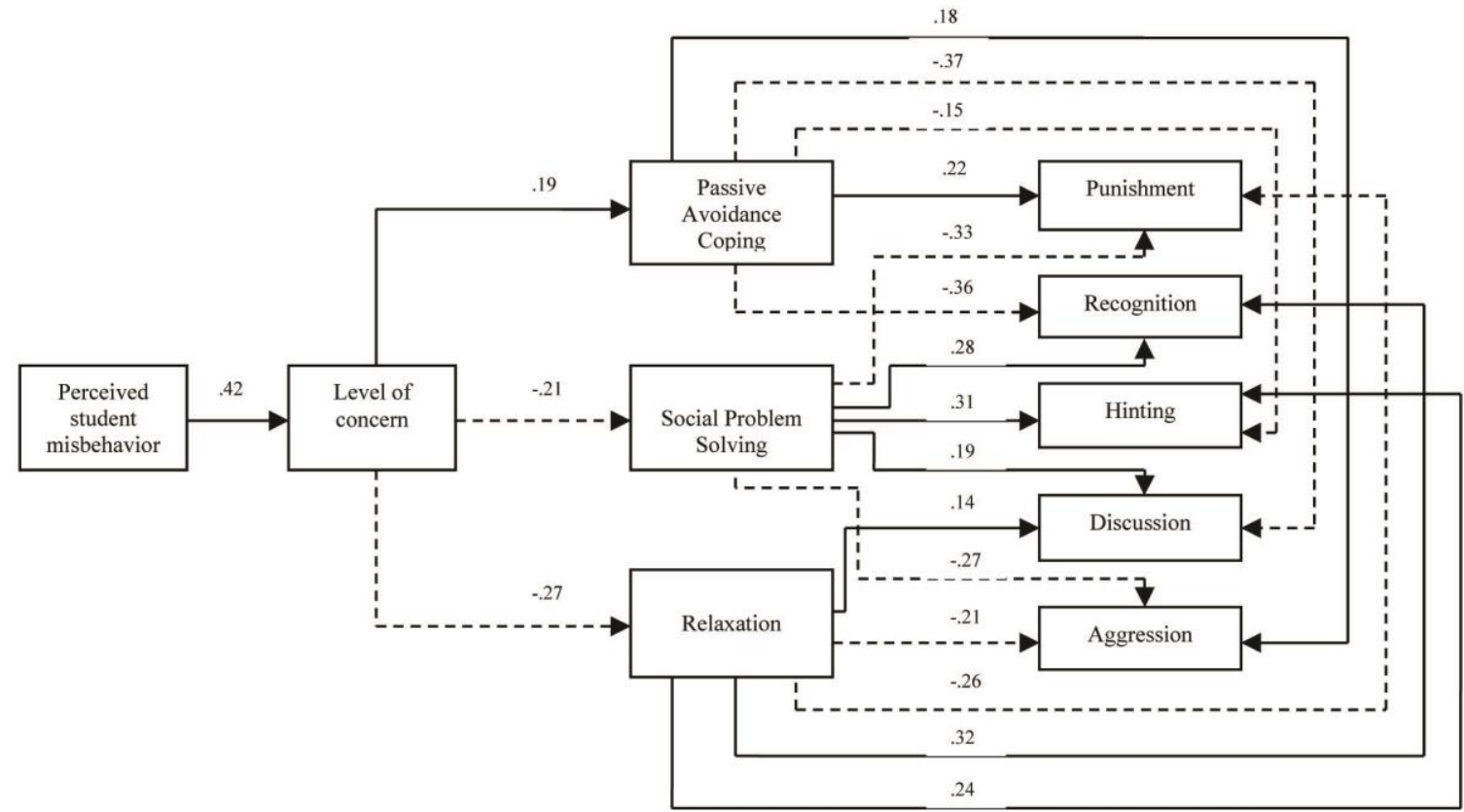

Figure 2. Relationships between perceived misbehavior, concern, coping responses and management techniques

Inspection of the statistically significant paths in the analysis indicates that teachers who are more concerned about student misbehavior they use more passive avoidant coping strategies (e.g. worry about what will happen to me, blame myself), and use less relaxation (e.g. look on the bright side of things and think of all that is good; relax, e.g. watch TV, play computer games, go for a walk), and social problem solving strategies (e.g. look for support and encouragement from others, work hard). 
In addition, the results show that the three coping styles were statistically significantly related to all of five classroom management techniques. The passive avoidant coping variable was positively significantly related to punishment $(\mathrm{r}$ $=.22, \mathrm{p}<.001)$, and aggression $(\mathrm{r}=.18, \mathrm{p}<.001)$, and was negatively significantly related to discussion $(\mathrm{r}=-.37, \mathrm{p}$ $<.001)$, recognition and rewards $(\mathrm{r}=-.36, \mathrm{p}<.001)$, and hinting $(\mathrm{r}=-.15, \mathrm{p}<.005)$. The path analysis also shows that teachers who use more passive avoidant coping strategies employ more punishment and aggression towards students, and use less discussion, recognition and rewards, and hinting. Therefore, the outcome is that their management becomes less productive. The results show that the two variables, social problem solving, and relaxation, were positively significantly related to recognition and rewards, discussion, and hinting variables, while they were passively significantly related to punishment and aggression variables. The findings indicate that teachers who use more relaxing activities, socially oriented problem solving coping strategies use more inclusive management techniques as recognition and rewards, discussion, and hinting towards students. Their management therefore becomes more productive.

The data from this study also shows that the use of aggression and punishment are a result of more student misbehavior or cause it. The results of this study are consistent with the findings of the previous research studies (Lewis, 2001; Lewis et al., 2005; Lewis, Roache, \& Romi, 2011; Roache \& Lewis, 2009; Van Dick \& Wagner, 2001) which indicate that teachers who use passive avoidant strategies employ more aggression and punishment techniques towards student misbehavior. Conversely, teachers who use more social problem solving and relaxation strategies use more inclusive management techniques such as recognition and reward, discussion, and hinting. The results of this study are also consistent with previously reported findings (Van Dick \& Wagner, 2001) that teachers with more adaptive coping strategies show a lower degree of burnout than teachers with avoidant coping strategies. Problem solving coping strategies increase teachers' sense of self-efficacy, reducing physical symptoms associated with stress, and reducing the rate of absenteeism from workplace as a result of burnout (Van Dick \& Wagner, 2001).

\section{Conclusion}

The results obtained from correlation analyses indicated that coping styles mediated the relationship between teachers' concerns about student misbehavior and their use of classroom management techniques. The findings indicated that when teachers perceived student misbehavior as a minor concern they tend to respond to misbehavior by manifesting the three coping strategies. Results also indicated that teachers who use passive avoidant strategies employ more aggression and punishment techniques towards student misbehavior, and use less discussion, recognition and rewards, and hinting. Conversely, teachers who use more social problem solving and relaxation strategies use more inclusive management techniques such as recognition and reward, discussion, and hinting. The findings indicate that Vietnamese teachers increased their use of recognition and reward, discussion, and hinting to react to classroom misbehavior. Vietnamese classrooms are seen as having most recognition and least punishment, and aggression. Misbehavior in classes relates to the greater use of punishment and aggression. It appears that teachers who employ poor management techniques, such as punishment and aggression contribute to their own problems by reacting with passive strategies that serve only to exacerbate the very problems they are intended to overcome or prevent (Roache \& Lewis, 2009). The results of the study show that Vietnamese teachers should be encouraged to minimize the level of student misbehavior and level of concern from schoolwork by decreasing their use of aggressive disciplinary techniques while by increasing levels of recognition and rewarding of appropriate behavior, as well as increasing levels of discussion with students through professional development programs.

\section{References}

Birch, S. H., \& Ladd, G. W. (1998). Children's interpersonal behaviors and the teacher-child relationship. Developmental Psychology, 34, 934-946. http://dx.doi.org/10.1037/0012-1649.34.5.934

Buchanan, J. (2010). May I be excused? Why teachers leave the profession. Asia Pacific Journal of Education, 30 , 199-211. http://dx.doi.org/10.1080/02188791003721952

Chan, D. W. (1998). Stress, coping strategies, and psychological distress among secondary school teachers in Hong Kong. American Educational Research Journal, 35(1), 145-163. http://dx.doi.org/10.3102/00028312035001145

Chan, D. W. (2006). Emotional intelligence and components of burnout among Chinese secondary school teachers in Hong Kong. Teaching and Teacher Education, 22, 1042-1054. http://dx.doi.org/10.1016/j.tate.2006.04.005

Cronkite, R. C., \& Moos, R. H. (1984). The role of predisposing and moderating factors in the stress teachers in Hong Kong. American Educational Research Journal, 35(1), 145-163.

Davidson, K. V. (2009). Challenges contributing to teachers stress and Burnout. Southeastern Teacher Educational Teacher, 2, 47-56. 
Friedman, I. A. (1994). Conceptualizing and measuring teacher-perceived student behaviors: Disrespect, sociability and attentiveness. Educational and Psychological Measurement, 54(4), 949-958. http://dx.doi.org/10.1177/0013164494054004011

Gao, L. (1998). Cultural context of school science teaching and learning in the People's Republic of China. Science Education, 82, 1-13. http://dx.doi.org/10.1002/(SICI)1098-237X(199801)82:1<1::AID-SCE1>3.0.CO;2-L

Hammarberg, A., \& Hagekull, B. (2006). Changes in externalizing and internalizing behaviors over a school-year: differences between 6-year-old boys and girls. Infant and Child Development, 15, 123-137. http://dx.doi.org/10.1002/icd.444

Hart, P. M., Wearing, A. J., \& Conn, M. (1995). Conventional wisdom is a poor predictor of relationship between discipline policy, student misbehavior and teacher stress. British Journal of Educational Psychology, 65(1), 27-48. http://dx.doi.org/10.1111/j.2044-8279.1995.tb01129.x

Henricsson, L., \& Rydell, A. M. (2004). Elementary School Children with Behavior Problems: Teacher-Child Relations and Self-Perception. A Prospective Study. Merrill-Palmer Quarterly, 50, 111-138. http://dx.doi.org/10.1353/mpq.2004.0012

Hyman, I., \& Snook, P. A. (2000). Dangerous schools and what you can do about them. Phi Delta Kappan, 81(7), 489-501.

Jin, L., \& Cortazzi, M. (1998). Dimensions of dialogue: Large classes in China. International Journal of Educational Research, 29, 739-761. http://dx.doi.org/10.1016/S0883-0355(98)00061-5

Kaplan, A., Gheen, M., \& Midgley, C. (2002). Classroom goal structure and student discruptive behavior. British Journal of Educational Psychology, 72(2), 191-212. http://dx.doi.org/10.1348/000709902158847

Kennedy, K. J. (1996). New challenges for civics and citizenship. ACT. Australia: ACSA.

Keung, H. (2005). The relation of gender-role classifications to the prosocial and antisocial behavior of Chinese adolescents. The Journal of Generic Psychology, 166, 189-192. http://dx.doi.org/10.3200/GNTP.166.2.189-202

Lazarus, R. S. (1993). Coping theory and research: Past, present, and future. Psychosomatic Medicine, 55, $234-247$. http://dx.doi.org/10.1097/00006842-199305000-00002

Lazarus, R. S., \& Folkman, S. (1984). Stress, appraisal and coping. New York: Springer.

Lewis, R. (1997). The Management Dilemma. The Council for Educational Research, Melbourne: ACER Press.

Lewis, R. (1999). Teachers coping with the stress of classroom discipline. Social Psychology of Education, 3, 155-171. http://dx.doi.org/10.1023/A:1009627827937

Lewis, R. (2001). Classroom management and student responsibility: the students' view. Teaching and Teacher Education, 17, 307-319. http://dx.doi.org/10.1016/S0742-051X(00)00059-7

Lewis, R., \& Loveggrove, M. N. (1987). What students think of teacher's classroom control techniques: Results from four studies. In J. Hastings \& J. Schwieso (Eds.), New directions in educational psychology, 2, 93-113. The Palmer Press.

Lewis, R., Roache, J., \& Romi, S. (2011). Coping styles as mediators of teachers' classroom management techniques. Research in Education, 85 (1), 53-68. http://dx.doi.org/10.7227/RIE.85.5

Lewis, R., Romi, S., Qui, X., \& Katz, Y. (2005). Teachers' classroom management and student misbehavior in Australia, China and Israel. Teaching and Teacher Education, 21, 729-741. http://dx.doi.org/10.1016/j.tate.2005.05.008

Lewis, R., Romi, S., Qui, X., \& Katz, Y. (2008). Students' reaction to classroom discipline in Australia, Israel, and China. Teaching and Teacher Education, 24, 715-724. http://dx.doi.org/10.1016/j.tate.2007.05.003

Lewis, R., Romi, S., Xing, Q., \& Katz, Y. (2005). Teachers' classroom discipline and student misbehavior in Australia, China, and Israel. Teaching and Teacher Education, 21, 729-741. http://dx.doi.org/10.1016/j.tate.2005.05.008

Lickona, T. (1996). Teaching respect and responsibility Reclaiming children and Youth. Journal of Emotional and Behavioral Problems, 5(3), 143-151.

McCormick, J., \& Shi, G. (1999). Teachers' attributions of responsibility for their occupational stress in the People's Republic of China and Australia. British Journal of Educational Psychology, 69(3), 393-407. 
http://dx.doi.org/10.1348/000709999157798

Menaghan, E. G., \& Merves, E. S. (1984). Coping with occupational problems: The limits of individual efforts. Journal of Health and Social Behavior, 25, 406-423. http://dx.doi.org/10.2307/2136379

Miller, A., Ferguson, E., \& Byrne, I. (2000). Pupils' caual attributions for difficult classroom behavior. Bristish Journal of Educational Psychology, 70, 85-96. http://dx.doi.org/10.1348/000709900157985

Ministry of Education and Training (MOET). (2010). School Violence in Vietnam. http://tailieu.vn/xem-tai-lieu/de-tai-bao-luc-hoc-duong-o-viet-nam.411893.html.

National Assembly of the Socialist Republic of Vietnam [NASRV] (2008). Education Law, No. 38/2008/QH11-2008. Hanoi: Education Press.

Oswald, U. (1995). Difficult to manage students: A survey of children who fail to respond to student management strategies in government schools. Educational Studies, 21, 265-276. http://dx.doi.org/10.1080/0305569950210208

Peng, S. S. (1993). Fostering student management and effort: Approaches used in Chinese schools. Paper presented at the Conference Name (April 12-16, 1993).

Roache, J. (2008). Strategies to ameliorate teacher stress, leadership in focus. The Journal for Australasian School Leaders, Victorian Principals Association, 12 (summer).

Roache, S., \& Lewis. R. (2011). Teachers' views on the impact of classroom management on student responsibility. Australian Journal of Education. 55(2), 132-146. http://dx.doi.org/10.1177/000494411105500204

Roache. J. E., \& Lewis. R. (2011). The carrot, the stick, or the relationship: What are the effective disciplinary strategies? European Journal of Teacher Education, 34(2), 233-248. http://dx.doi.org/10.1080/02619768.2010.542586

Romi, S., \& Freund, M. (1999). Teachers', students' and parents' attitudes towards discruptive behavior problems in high school; a case study. Educational Psychology, 19(1), 53-70. http://dx.doi.org/10.1080/0144341990190104

Romi, S., Lewis, R., \& Katz, Y. (2009). Student responsibility and classroom discipline in Australia, China and Israel. Compare, 39(4), 439-452. http://dx.doi.org/10.1080/03057920802315916

Van Dick, R., \& Wagner, U. (2001). Stress and strain in teaching: A structural equation approach. British Journal of Educational Psychology, 71, 243-259. http://dx.doi.org/10.1348/000709901158505 